\title{
A Área de Ensino após a avaliação quadrienal da CAPES: reflexões fora da caixa, inovações e desafios em 2017
}

\section{RESUMO}

Tania C. Araújo-Jorge taniaai@ioc.fiocruz.br 0000-0002-8233-5845 Laboratório de Inovações em Terapias, Ensino e BioprodutosLITEB, Instituto Oswaldo Cruz, Fundação Oswaldo Cruz-Fiocruz, Rio de Janeiro, Coordenadora da Área de Ensino na CAPES, docente do Programa de Pós-Graduação em Ensino em Biociências e SaúdeFiocruz.

Hilda Helena Sovierzoski hovierzoski@gmail.com 0000-0001-8158-6733

Instituto de Ciências Biológicas e da Saúde, Universidade Federal de Alagoas-UFAL, Coordenadora adjunta de Mestrados Profissionais da Área de Ensino na CAPES

docente do Programa de Pós-

Graduação em Ensino de Ciências e Matemática-UFAL.

Marcelo de Carvalho Borba mborba@rc.unesp.br 0000-0003-3101-5486

Grupo de Pesquisa em Informática, outras mídias e Educação

Matemática da Universidade

Estadual Paulista Júlio de Mesquita

Filho campus Rio Claro,

Coordenador adjunto da Área de

Ensino na CAPES, docente do

Programa de Educação

Matemática-UNESP-RC.
Qualificar pessoas para atuar na formação de formadores em Ensino/Educação no Brasil é uma ação por si, de grande relevância social. Em 2017 a Área de Ensino registrou 157 programas, dos quais 140 foram avaliados: 139 individuais e um em rede, a REAMEC, Rede Amazônica de Ensino de Ciências e Matemática. Provocamos aqui reflexões sobre a avaliação tais como: inovações: 1- A avaliação da produção intelectual integral, com quatro "Qualis"; 2- O indicador pontos totais por docente permanente por ano; 3- O uso combinado de indicadores; 4- A criação do Qualis-Educacional; 5- A ficha de acompanhamento da internacionalização. Destacamos redes de cooperação em ensino e pesquisa (INCT-Ensino) e sugerimos mudanças na avaliação, entre as quais mais cooperação e menos competição, e maior valorização da Inserção Social. Depositamos na comunidade da Área de Ensino uma enorme confiança sobre seu papel na resistência da sociedade por uma educação pública e de qualidade.

PALAVRAS-CHAVE: ensino, avaliação, inovação, indicadores, cooperação. 


\section{INTRODUÇÃO}

Educar é impregnar de sentidos tudo o que fazemos.

Paulo Freire

Qualificar pessoas para atuar na formação de formadores em Ensino/Educação no Brasil é uma ação por si, de grande relevância social, num país atrasado cinco séculos em relação às primeiras Universidades do mundo (ano de 737 para a Universidade Ez-Zitouana em Túnis, ano 1088 para a Universidade de Bologna na Itália). Em 1759, quando já havia mais de 10 Universidades nas Américas, o Brasil contava com 17 "escolas de primeiras letras", introduzidas por padres jesuítas. O primeiro Ministério de Educação surgiu em 1930, e a primeira Universidade (Universidade de São Paulo) surgiu em 1934, ano em que o direito universal à Educação foi assegurado constitucionalmente e definido como dever do Estado. Portanto, avaliar a pós-graduação em Ensino deve ser uma ação feita com uma reflexão desse pano de fundo sobre a enorme e histórica dívida social do país para com seu povo em termos educacionais.

A Área de Ensino da Coordenação de Aperfeiçoamento de Pessoal de Nível Superior (CAPES) foi criada em 6 de junho de 2011 pela Portaria no 83/2011, incorporando todos os Programas de Pós-Graduação (PPG) da Área de Ensino de Ciências e Matemática, que funcionou com esse escopo nos onze anos anteriores, e que já teve sua origem estudada e registrada em diversas publicações (editorial de Nardi, 2015). Assim, foi a Área de Ensino de Ciências e Matemática que nucleou a atual Área de Ensino, mancando-a com suas referências e a experiência de organização e avaliação. Num período de 17 anos, a contar da criação formal da Área de Ensino de Ciências e Matemática, o número de programas passou dos sete iniciais para 160, chegando a 179, quando se incluem todas as sedes de PPG e suas instituições associadas, pois além de programas isolados em diversas Instituições de Ensino Superior (IES), a Área conta com experiências de duas, três, quatro e até 18 IES associando-se em redes e parcerias.

Desde 2011, a Área passou por duas avaliações periódicas por nós coordenadas, cujos relatórios encontram-se disponíveis (Araújo-Jorge e Roças, 2013; Araújo-Jorge et al., 2017): a trienal de 2013, e a quadrienal de 2017 (AQ). Na avaliação 2010-2012 a Área de Ensino computou 104 PPG, dos quais 74 foram plenamente avaliados, ou seja, contavam com mais de um relatório anual no sistema Coleta-CAPES. A avaliação do Sistema Nacional de Pós-Graduação (SNPG) tornou-se quadrienal por força da Resolução no 05 do Conselho Superior da CAPES, de 11 de dezembro de 2014. No quadriênio 2013-2016, registrado na Plataforma Sucupira o número subiu para 157 programas ativos, dos quais 140 foram plenamente avaliados: 139 individuais e um em rede, a REAMEC, Rede Amazônica de Ensino de Ciências e Matemática.

Para surpresa de muitos, a Área de Ensino integra a Grande Área Multidisciplinar da CAPES, e nisso se distancia da Área de Educação, sua Área-mãe, que integra a Grande Área de Humanidades. Essa opção foi tomada em 2008, quando da criação da Grande Área Multidisciplinar, integrada hoje por cinco Áreas, que avaliaram 684 PPG na quadrienal: Interdisciplinar (335 PPG), Ensino (140 PPG), Ciências Ambientais (112 PPG), Biotecnologia (61 PPG) e Materiais (36 PPG). 
A avaliação do SNPG é responsabilidade da Diretoria de Avaliação da CAPES (DAV), e em 2017 teve a dimensão de 4.175 programas (PPG) de mestrado e doutorado acadêmicos e mestrado profissional, parte deles em rede. A característica central da avaliação da Pós-Graduação é ser realizada por pares (comissão de especialistas da Área, no caso Ensino), com base em informações anuais públicas e transparentes, registradas em separado por cada PPG na plataforma comum do SNPG, a Plataforma Sucupira. Os relatórios foram analisados pela Comissão de Área (CA), num esforço concentrado de análise comparativa da evolução e do estado da arte em cada Área, posteriormente revisado pelo Conselho Técnico Científico do Ensino Superior (CTC-ES), que reúne todas as Áreas. Os PPG se distribuem em notas 3 (Regular), 4 (Bom) e 5 (Muito Bom), e destes últimos se destacam programas excelentes, com notas 6 e 7, que constituem referências para as Áreas em termos de internacionalização e de nucleação de novos programas e docentes.

Concluímos a redação desse artigo imediatamente após o 50 Seminário de Acompanhamento da Área de Ensino, realizado nos dias 8 a 10 de novembro de 2017. Todos os programas que apresentaram pelo menos uma turma de egressos foram avaliados (podendo ter notas alteradas) e/ou acompanhados (acompanhamento de atividades para verificação da fidelidade na implantação do novo curso). Como o relatório da avaliação está bastante completo, nossa intenção neste artigo é provocar "reflexões fora da caixa" sobre esse processo: no que a Área inovou durante a avaliação? O que pode ser necessário alterar para o próximo quadriênio?

\section{O crescimento da Área em números}

A criação da Área em 2000 se deu pela migração de sete programas acadêmicos já consolidados, com mestrado e doutorado, da Área de Educação para a área de Ensino de Ciências e Matemática (Figura 1). Já em 2001 iniciou-se a nucleação de mestrados profissionais na Área de Ensino, movimento que se iniciou na Área de Educação apenas uma década depois. A Figura 1 mostra que as duas modalidades de programas foram crescendo paralelamente, tendo a modalidade de mestrados profissionais despontado como majoritária, contribuindo hoje com $56 \%$ da Área de Ensino. Mestrados acadêmicos isolados compreendem 25\% dos PPG e os mestrados com doutorado são responsáveis por 16\%. Há 6 doutorados isolados (3\% da Área), que eleva para 35 o número de doutorados ativos na Área.

Uma diferença importante entre as Áreas de Educação e de Ensino se refere à formação de graduação e de pós-graduação dos docentes dos seus PPG, muito mais multidisciplinar na Área de Ensino, tal como previsto pela inserção da Área na grande Área Multidisciplinar. Outra característica da Área de Ensino é a inserção de muitos de seus docentes em outros PPG, em suas respectivas áreas disciplinares de origem, garantindo um adequado diálogo entre áreas. A AQ mostrou que dos 2.602 docentes totais registrados, apenas $26(0,9 \%)$ não tinham a titulação de Doutorado, dado que as orientações da CAPES permitem essa atuação no mestrado profissional. No entanto, buscando assegurar cada vez maior qualidade, desde 2015 a diretriz da Área de Ensino é inserir apenas doutores em seus PPG profissionais. A maioria dos docentes da Área são mulheres (55\%) e foram registrados 167 bolsistas de produtividade do CNPq. 
Com tais dimensões, 160 programas ativos, 179 coordenadores de PPG, mais de 2.600 docentes, a Área tem como sua maior contribuição a formação de mestres e doutores para atuar nas universidades brasileiras, na formação de formadores educadores. $O$ relatório da $A Q$ mostrou que nesses 16 anos foram formados 10.375 mestres e 1.355 doutores nos PPG da Área, e que ainda há uma demanda por vagas oferecidas nos processos seletivos quatro a cinco vezes maior do que o disponível.

Figura 1: Crescimento anual do número de Programas de Pós-Graduação na Área de Ensino, segmentado por modalidade (2000-2017).

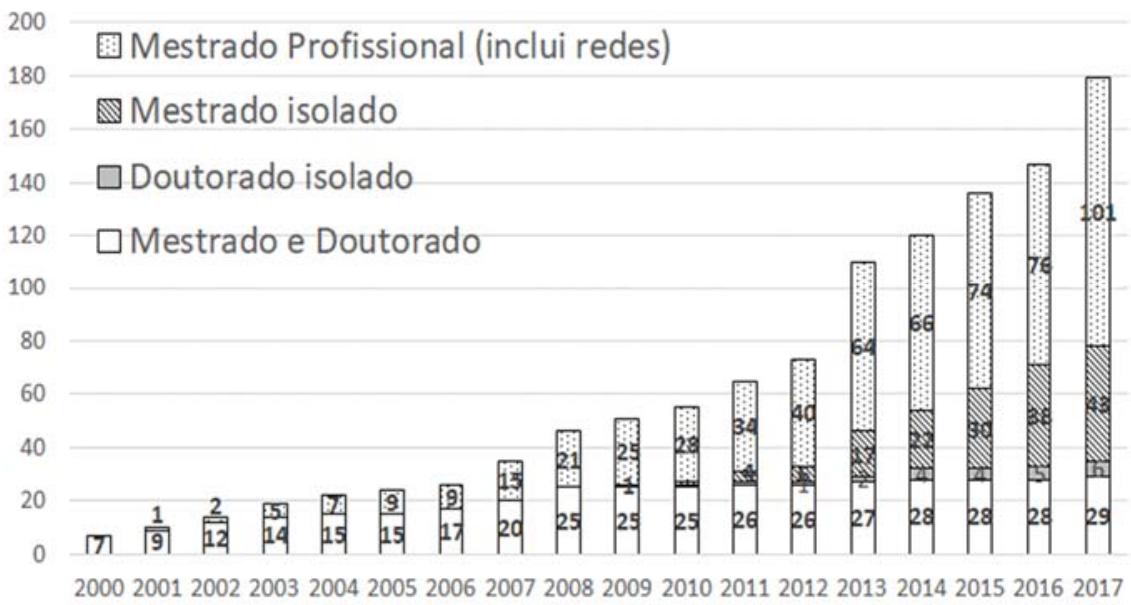

\section{Há subjetividade na avaliação, para além dos números? Há sentido pedagógico?}

A AQ é um processo complexo, que analisa cinco quesitos e thes atribui pesos diferentes: a proposta do programa (quesito 1), seu corpo docente (quesito 2), seus resultados em termos de titulados (quesito 3 ), a produção intelectual e técnica do programa, incluindo corpo docente e discente (quesito 4) e a inserção social do programa (quesito 5). Cada quesito se desdobra em itens, todos descritos pormenorizadamente no documento de Área, e com indicadores também conhecidos, tanto pelo documento de Área como pelo relatório da quadrienal. As métricas quantitativas são registradas, definindo as fronteiras entre os conceitos insuficiente, fraco, regular, bom e muito bom. Assim, a avaliação é feita com cinco conceitos que podem ser atribuídos a cada item, bem como a cada quesito. Ao final, infere-se uma tendência da avaliação, também expressa nos conceitos, e depois transformada em nota do Programa (http://avaliacaoquadrienal.capes.gov.br/home/sai-o-resultado-da-1a-etapa-daavaliacao-quadrienal-2017). Desse modo, essa avaliação se transforma numa nota final de 1 a 5, em que as duas mais baixas ( 1 e 2) descredenciam o PPG do SNPG, e as 3 maiores ( 3,4 e 5$)$ mantém o PPG no sistema. As notas 6 e 7 são atribuídas apenas a PPG com doutorado, que atingem a nota 5 na primeira fase da avaliação, e se destacam depois por atributos de excelência, internacionalização e solidariedade. As notas se refletem no suporte financeiro da CAPES aos programas, expressando-se em número de bolsas e em recursos de custeio e capital, sendo 
diferente para cada nota, e também diferente para os programas de excelência, notas 6 e 7 .

Do relatório da avaliação quadrienal da Área de Ensino, extraímos o seguinte trecho:

A avaliação foi bastante objetiva, com muitos critérios e muito rigor, mas sem rigidez, guardando também muita subjetividade e indicadores qualitativos. Portanto, a percepção do consultor falou mais alto do que uma análise simples e fria de indicadores quantitativos do processo (sua "numerologia"). As Comissões de Avaliação trabalharam com a diretriz de realizar uma avaliação construtiva, que fortalecesse a cooperação, mais do que a competição, entre Programas da Área, evitando os "ranqueamentos". Uma avaliação que buscou identificar os pontos fortes dos programas, reforçandoos, assim como identificar seus pontos fracos, ver como as coordenações e docentes estão lidando com tais fragilidades, e recomendar aperfeiçoamentos. Um sentido pedagógico e não punitivo. Os pareceres procuraram evidenciar todos esses pontos e, ao final, cada Programa passou por três possibilidades: manutenção da nota, progressão para uma nota superior, ou regressão à uma nota inferior. (...) Hoje a Área está muito mais forte e harmônica, mais organizada, cooperando para enfrentar com ânimo e esperança as adversidades atuais e por vir, fazendo sempre melhor o que seus docentes e discentes podem e sabem fazer de melhor.

Esse trecho destaca uma das principais preocupações que dominou o processo de $A Q$ na Área de Ensino: a percepção da evolução individual de cada PPG, sua tendência de crescimento, e seu papel na Área e no contexto social local. Assim, por vezes, indicadores quantitativos foram secundarizados em relação a indicadores qualitativos, que indicavam a função social daquele determinado PPG. Nenhum PPG foi penalizado por um indicador específico, tendo sido usada uma combinação de indicadores para destacar os pontos fortes e sugerir melhorias em pontos fracos.

Dessa avaliação emergiram os números e as dimensões da Área, em termos de resultados do trabalho dos PPG. A Tabela 1, levemente modificada a partir da constante no relatório, expõe os principais dados analisados.

Tabela 1: Dimensão da Área de Ensino - Avaliação Quadrienal de 2017*

\begin{tabular}{|l|c|l|c|}
\hline $\begin{array}{l}\text { Número de coordenadores } \\
\text { na Área (sedes e } \\
\text { associadas) }\end{array}$ & 179 & Número de programas avaliados (AQ) & 140 \\
\hline $\begin{array}{l}\text { Número de programas } \\
\text { acadêmicos avaliados (AQ) }\end{array}$ & 67 & $\begin{array}{l}\text { Número de programas profissionais } \\
\text { avaliados (AQ) }\end{array}$ & 73 \\
\hline Docentes totais na Área (AQ) & 2.602 & Egressos totais na Área (AQ) & 5.941 \\
\hline $\begin{array}{l}\text { Docentes com bolsa de } \\
\text { produtividade do CNPq (AQ) }\end{array}$ & 167 & $\begin{array}{l}\text { Egressos mestres (AQ) } \\
\text { Egressos doutores (AQ) }\end{array}$ & $\begin{array}{c}5.033 \\
908\end{array}$ \\
\hline $\begin{array}{l}\text { Número de periódicos } \\
\text { registrados (AQ) }\end{array}$ & 2.452 & Número de livros registrados (AQ) & 2.534 \\
\hline $\begin{array}{l}\text { Número de artigos A1-B5 } \\
\text { (AQ) }\end{array}$ & 13.104 & Número de livros classificados (AQ) & 627 \\
\hline Número de artigos A1-B1 & 7.482 & Número de livros L3-L4 & 504 \\
\hline $\begin{array}{l}\text { Número de eventos } \\
\text { registrados (AQ) }\end{array}$ & 1.842 & $\begin{array}{l}\text { Número de Produtos Educacionais } \\
\text { registrados-MP }\end{array}$ & 3.062 \\
\hline $\begin{array}{l}\text { Número de Eventos E1-E2 } \\
\text { (AQ) }\end{array}$ & 1.091 & $\begin{array}{l}\text { Número de Produtos Edu1-Edu2-MP } \\
\text { (AQ) }\end{array}$ & 446 \\
\hline
\end{tabular}

Fonte: Tabela 1, relatório da avaliação quadrienal(AQ), modificado pelos autores. 
Mas, de fato, o que significam os números? $\mathrm{O}$ que dizem as mais de 5 mil dissertações? Os mais de 13 mil artigos publicados em periódicos? Os mais de 2.500 livros registrados na Plataforma Sucupira? Como avaliar além dos números?

Essas são perguntas chave no momento atual. Não basta sistemas de estratificação de produtos por qualidade, sejam periódicos, livros, eventos ou materiais educacionais (e a Área de Ensino aplicou tais sistemas). Não bastam esses sistemas "Qualis", pois continuam gerando números, e não ideias, informações, conhecimentos qualitativamente acessíveis. Conhecemos sim a Área de Ensino por seus números. Mas é hora de secundarizarmos um pouco esses números e de nos concentrarmos nas proposições, nas ações e nas inovações por trás deles. É hora de tentarmos olhar e ver, mais, além dos números. Como?

\section{Inovações da Área de Ensino na Quadrienal 2017}

A maior novidade do processo de avaliação (http://avaliacaoquadrienal.capes.gov.br/) foi o uso da Plataforma Sucupira (https://sucupira.capes.gov.br), que impactou o processo como um todo. Qualquer cidadão pode ter acesso às informações registradas pelos Programas, ponto a ponto, item a item, e a CAPES disponibilizou as planilhas de dados brutos extraídas

da

plataforma (http://avaliacaoquadrienal.capes.gov.br/home/planilhas-de-indicadores) para cada uma das 49 Áreas de avaliação. Os documentos de cada Área (http://avaliacaoquadrienal.capes.gov.br/documentos-de-area), bem como os relatórios de cada Área (http://avaliacaoquadrienal.capes.gov.br/home/sai-oresultado-da-1a-etapa-da-avaliacao-quadrienal-2017) também estão disponíveis. Tal grau de transparência só foi possível pelo fato da avaliação contar com a nova plataforma armazenando a informação.

Todo o SNPG se beneficiou desse novo momento e do novo patamar de dados disponível para que os consultores e consultoras pudessem trabalhar melhor justamente na avaliação mais qualitativa da Área, e não perdessem muito tempo em calcular números e métricas, que já vinham parcialmente processados e, depois de um tempo de acomodação e costume no uso das planilhas, permitia a qualquer um localizar dados e indicadores relevantes. Justamente por estar nesse novo patamar, dentre dezenas de indicadores disponíveis, a Área de Ensino pode destacar cinco inovações que marcaram esse processo: 1- $A$ avaliação da produção intelectual qualificada integral, com quatro "Qualis" e não o uso exclusivo do Qualis-periódicos; 2- a construção do indicador "Pontos totais/DP/ano" (pontos totais por docente permanente por ano), que integra toda a produção intelectual e técnica e permite a construção de um padrão comparativo tanto para o programa analisar sua evolução em relação à ultima avaliação, quanto uma comparação com os demais programas da Área, e até mesmo a aplicação como parâmetro complementar para credenciamento de docentes; 3- O uso combinado de indicadores; 4- a criação do Qualis-Educacional; e 5- a criação da ficha de acompanhamento da internacionalização.

\section{1- A avaliação da produção intelectual qualificada integral, com quatro "Qualis".}

A produção intelectual e técnica dos PPG da Área de Ensino foi avaliada segundo a classificação dos diferentes tipos de produtos em estratos hierarquizados conforme a Tabela 2: quatro estratos para artigos completos em 
anais de eventos (de 5 a 20 pontos), quatro estratos para livros e capítulos de livros (de 10 a 75 pontos), cinco estratos para produtos educacionais nos mestrados profissionais (de 15 a 100 pontos), e sete estratos para artigos em periódicos (de 10 a 100 pontos). Para capítulos de livros foi aplicada uma "trava" máxima de dois capítulos/ por autor/ por obra, e para trabalhos completos em anais de eventos também, considerando-se até três vezes o número de artigos registrados pelo PPG.

Os pontos dos diferentes tipos de produtos foram divididos pelo número de docentes permanentes do PPG e pelo número de anos avaliados (DP/ano). Desse modo, os produtos foram pontuados de acordo com sua maior ou menor "qualidade" e a produção global do PPG foi analisada e dividida pelo seu núcleo central, os docentes permanentes, aqueles com maior dedicação ao PPG. A Figura 2 segmenta em cores e os pontos os resultados de 15 IES, para efeito ilustrativo e conceitual.

Figura 2: Exemplo de segmentação da pontuação em produção intelectual de 15 programas acadêmicos.

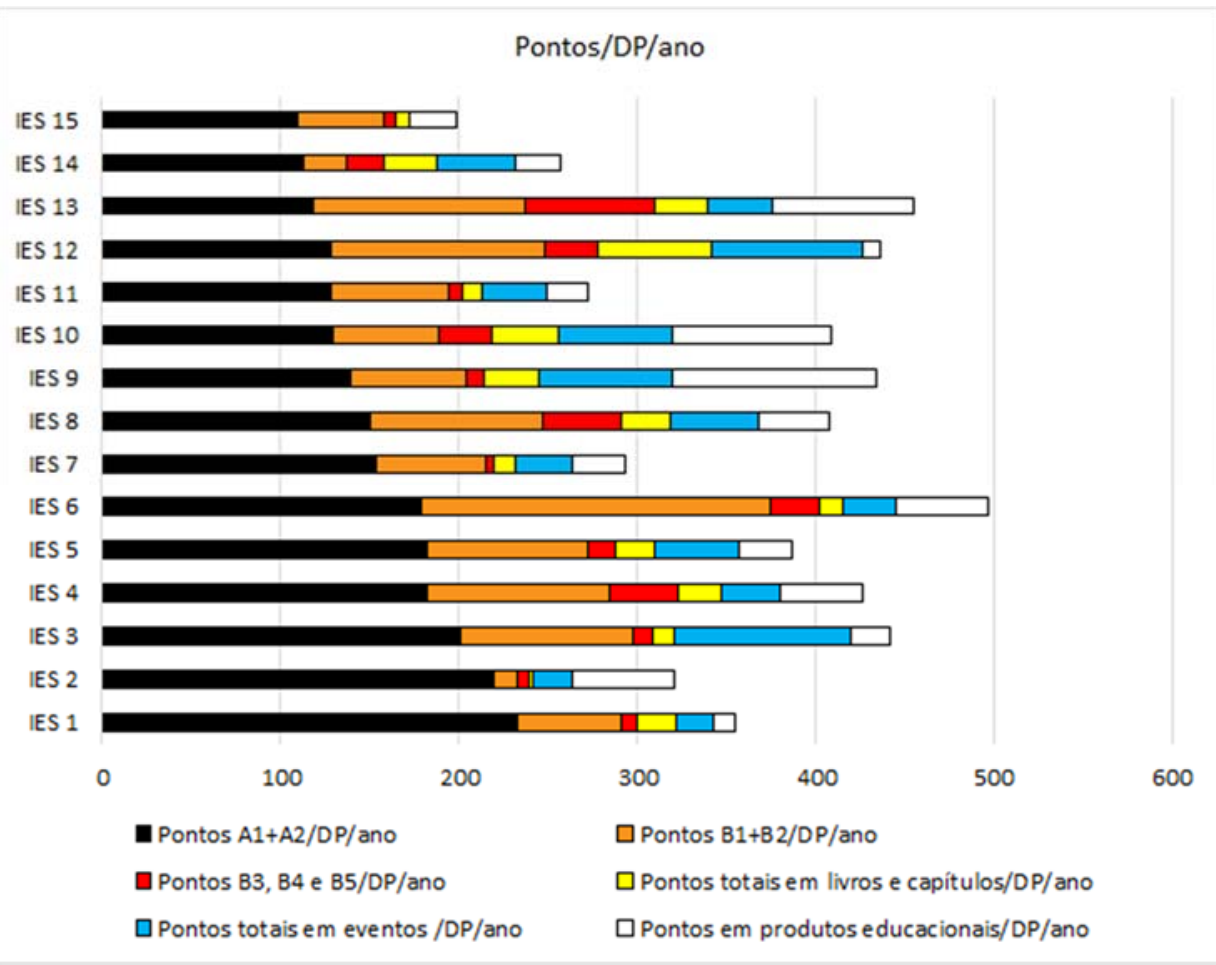

Analisando a Figura 2 vemos que a IES 6 foi a que mais produziu (perto de 500 pontos/DP/ano), e 4/5 dessa produção é em artigos. No entanto, a IES 1 produziu ao todo um pouco menos, porém com maior densidade de pontos nos estratos $\mathrm{A} 1+\mathrm{A} 2$ (parte preta da coluna). O segmento branco das 15 barras é bastante distinto entre elas, indicando que a produção técnica destes PPG é bem diferente, e que o PPG 9 é o que apresenta maior "vocação" ou "empenho" na produção técnica. Os pontos em livros e capítulos impactaram pouco na produção dessas IES, sendo mais importante na IES 12 (segmento amarelo das barras).

Essa estratégia de valorizar toda a produção foi muito interessante, e reflete o acúmulo que Área tem sobre a importância da diversidade na produção intelectual. Verifica-se que para alguns programas, mesmo com a "trava" no 
número de trabalhos completos em anais de eventos computados, foi importante o registro desse tipo de produção (ex: IES 3- segmento azul). Assim, de acordo com a indução de valorização proposta pelo documento de Área, os PPG trabalharam no quadriênio priorizando a produção maior ou menor num dado tipo de produto, sabendo que todos iriam ser computados, ainda que com valores diferentes (Figura 2).

\section{2- O indicador "Pontos totais/DP/ano" (pontos totais por docente permanente por ano).}

Para analisar uma área tão diversa em temas e modalidades de PPG, foi interessante adotar um indicador de integralização da produção intelectual e técnica. A escala do eixo $x$ da Figura 2 dá a dimensão desse indicador. Ele permitiu a construção de um padrão de comparação interna, possibilitando a percepção da evolução do PPG em relação à sua última avaliação (na medida em que as planilhas de 2013 haviam sido preservadas), quando em uma comparação com os demais programas da Área. Alguns programas têm tomado esse padrão como um indicador útil para o credenciamento de novos docentes e o descredenciamento de docentes, tal como apontado no relatório.

\section{3- $O$ uso combinado de indicadores.}

Dependendo do grupo de comparação dos PPG, por exemplo, entre os programas de nota 3 , ou de nota 5 , foi possível utilizar uma combinação de indicadores, buscando aquele que melhor se aplicasse a cada caso. Assim, para definir se um programa acadêmico mantinha ou atingia a nota 5 ou 6, o indicador de pontos em artigos A1+A2/DP/ano era mais relevante do que para definir se um PPG manteria nota 3 ou 4, quando o indicador pontos totais/DP/ano era mais indicado.

\section{4- A criação do Qualis-Educacional.}

Com a criação dos mestrados profissionais na Área de Ensino, desde 2001, foi implantado o conceito de que para cada dissertação, deveria corresponder também um material educacional, produto ou processo, aplicável ao contexto do trabalho do mestrando-professor. Isso está previsto no Documento da Área e desse modo se previa um impacto mais imediato e direto na atividade profissional do discente/egresso. A produção de materiais educacionais é dirigida a determinados públicos, envolvendo processos de formação em ambientes de ensino formal (escolas e instituições educacionais nos diversos níveis de ensino) ou não formal (museus e centros de ciência, arte e cultura, centros de saúde e similares, entre outros).

Durante o quadriênio um grupo de trabalho de consultores da Área se dedicou ao debate sobre os critérios para avaliação desses produtos, e ao final de 2016 o Qualis-Educacional ficou pronto. Foi testado plenamente nos programas profissionais, e no próximo quadriênio será aplicado a toda a Área, para programas acadêmicos e profissionais, seguindo a decisão tomada pelos coordenadores no Seminário de Área de 2017.

Todo material educacional pode ser avaliado, mas apenas foram computados para fins de pontuação e de comparação entre vários PPG aqueles materiais associados às dissertações dos mestrandos (trabalho de final de curso) que estivessem em autoria com discentes mestrandos. Essas foram "travas" que asseguraram uma análise de qualidade justamente nos resultados mais 
importantes da pós-graduação: a formação discente refletida em sua produção aplicada.

Para efeito da classificação, foram considerados produtos como: mídias educacionais; protótipos educacionais e materiais para atividades experimentais; propostas de ensino; material textual (livros didáticos ou paradidáticos e outros); materiais interativos; atividades de extensão (cursos, oficinas e outros); desenvolvimento de aplicativos. Foram avaliados somente os produtos educacionais declarados na Plataforma Sucupira que possuíam uma URL própria, estando em acordo com a política de visibilidade prevista para as dissertações, teses e produtos educacionais gerados na Área. Os produtos precisavam estar registrados preferencialmente em formato digital (pdf ou outro) e com link disponível no sitio internet da instituição.

Não foram considerados para a classificação produtos como: editoria, posfácio, prefácio/apresentação, editorial, tradução de obras, patentes, organização de eventos, artigos em revistas de divulgação científica, apresentação de trabalho, outros produtos registrados, serviços técnicos.

Além do vínculo ao trabalho discente e à existência de URL própria, o QualisEducacional se baseou em quatro critérios da classificação: (i) validação (comitê ad hoc, por órgão de fomento ou por banca de dissertação); (ii) registro em sistema de informações em âmbito nacional ou internacional (ISBN, ISSN, ANCINE, Registro de Domínio, Certificado de Registro Autoral, registro ou averbação na Biblioteca Nacional, registros de patentes e marcas submetidos ao INPI). O registro se concretiza com vínculo aos repositórios em Instituições Nacionais, Internacionais, Universidades, ou domínios do governo na esfera local, regional ou federal (Portal do Professor, Banco Internacional de Objetos Educacionais, Vérsila Biblioteca Digital, Arca-Fiocruz, RIVED, LabVirt-USP, Multimeios, Escola Digital, Biblioteca Digital de Ciências-Unicamp, ChemCollective-USA, ITSON-México, JORUM-UK, EduCAPES-Brasil); (iii) uso em sistemas educacionais/de saúde (sim ou não em sistema local, municipal, estadual, nacional ou internacional); e (iv) acesso on line (sem acesso, acesso via rede fechada; acesso por Portal nacional ou internacional, Youtube, Vimeo e outros com acesso público e gratuito; acesso público e gratuito pela página do programa; acesso público e gratuito por Repositório institucional nacional ou internacional).

\section{5- A criação da ficha de acompanhamento da internacionalização.}

A avaliação da internacionalização foi crucial para a diferenciação dos programas e a listagem dos itens relevantes auxiliou bastante a perceber a evolução dos programas em termos de alcance ou implementação plena de cada item. Foram eles: a) Desempenho intelectual - Pontos A1+A2/DP/ano; b) Desempenho intelectual - Pontos A1+A2+B1/DP/ano; c) Livros e capítulos em idioma estrangeiro?; d) Há trabalhos com mais de 5 páginas/eventos em língua estrangeira?; e) Há grupo internacional cooperante/Qual?; f) Existem co-autorias internacionais na produção intelectual? Sim, não, quais e quantas?; g) Há participação docente em eventos internacionais?; h) Há participação discente em eventos internacionais?; i) Há participação discente em estágios internacionais?; j) $\mathrm{O}$ Programa recebe discentes estrangeiros? Com qual fonte de bolsas?; k) Recebe docentes estrangeiros? Com qual fonte de bolsas?; I) Há teses em co-tutela?; m) Há participação docente em comissões internacionais?; n) Há consultorias a órgãos internacionais?; o) Há docentes com pós-doutorado no exterior?; p) Há 
convênios/projetos com colaboração estrangeira?; q) O sitio internet do programa se apresenta também em idioma estrangeiro?

Essa experiência nos levou a propor no Seminário de Área realizado em novembro de 2017 que ficha similar fosse adotada para o quesito de Inserção Social, proposta que foi aprovada e ampliada. No caso da ficha de Inserção Social, os itens identificados como relevantes para captura de informações, como público alvo, ações realizadas, dados quantitativos, entre outros, foram: a) projetos e atividades de extensão, completando a missão universitária; b) atividades de divulgação dos seus resultados de pesquisa, ensino e extensão para a sociedade; expressão das seguintes outras dimensões de "impacto": c) impacto social direto dos egressos do programa: formação de recursos humanos qualificados para a Administração Pública ou a sociedade que possam contribuir para o aprimoramento da gestão pública e a redução da dívida social, ou para a formação de um público que faça uso dos recursos da ciência e do conhecimento no melhoramento das condições de vida da população e na resolução dos mais importantes problemas sociais do Brasil; d) impacto educacional, expressando a contribuição para a melhoria da educação básica e superior, o ensino técnico/profissional, a formação continuada, formação em serviço, a educação permanente e para o desenvolvimento de propostas inovadoras de ensino, em espaços formais e não formais; e) impacto tecnológico, expressando a contribuição para o desenvolvimento local, regional e/ou nacional destacando os avanços gerados nos setores educacional, social, do trabalho empresarial e outros; disseminação de técnicas e de conhecimentos; f) impacto econômico, abordando a contribuição para maior eficiência nas organizações públicas ou privadas, tanto de forma direta como indireta; g) impacto na saúde, com contribuição para a formação de recursos humanos qualificados para a gestão e atenção à saúde bem como na formulação de políticas específicas da Área da Saúde; h) impacto cultural, expressando contribuição para a formação de recursos humanos qualificados para o desenvolvimento cultural, formulando políticas culturais e ampliando o acesso à cultura e ao conhecimento; i) impacto artístico pela contribuição para a formação de recursos humanos qualificados para o desenvolvimento artístico, formulando propostas e produtos inovadores; j) impacto profissional expressando a contribuição para a formação de profissionais que possam introduzir mudanças na forma como vem sendo exercida a profissão, com avanços reconhecidos pela categoria profissional; k) impacto legal pela contribuição para a formação de profissionais que possam aprimorar procedimentos e a normatização na área jurídica, em particular entre os operadores do Direito, com resultados aplicáveis na prática forense; I) impacto ambiental pela contribuição para a formação de profissionais que possam atuar nas diferentes frentes relacionadas às questões ambientais, destacando a inserção e a disseminação de técnicas e de conhecimentos nos setores educacional, social, do trabalho empresarial e outros; $\mathrm{m}$ ) impacto por contribuir para a formação de lideranças, acadêmicas e sociais; $n$ ) impacto político e regional, pela contribuição para mudanças em políticas públicas locais ou regionais; o) ações transformadoras realizadas pelo corpo docente do PPG; p) nucleação de novos PPG em Ensino; q) outros impactos considerados pertinentes pelo PPG como contribuição da Área à sociedade, respeitando especificidades que não foram contempladas na lista acima.

É importante realçar que vários dos itens acima listados são frutos de uma produção coletiva, realizada antes e durante o seminário. Diversas comissões se reuniram nos últimos dois anos e ajudaram a gerar várias das ideias acima. Nos 
dias anteriores ao Seminário, os autores deste artigo elaboraram várias propostas para serem discutidas. Os diversos grupos que trabalharam durante o Seminários, assim como as plenárias, consolidaram ou transformaram diversas das ideias apresentadas.

\section{Redes de cooperação em Ensino e em Pesquisa emergiram dos relatórios dos programas na avaliação quadrienal}

$O$ relatório da $A Q$ também revelou algumas experiências marcantes de cooperação, tanto no campo do ensino, diretamente ligado ao aumento da escala de oferta de vagas para doutorado ou mestrado, quanto no campo da pesquisa, em diversos temas que são trabalhados por muitos PPG na Área. As redes de cooperação para oferta de vagas para a pós-graduação, tanto na modalidade acadêmica, como por exemplo o Doutorado na Amazônia que registra o grande sucesso da REAMEC, quanto na modalidade profissional, como o Mestrado Profissional em Educação Profissional e Tecnológica aprovado em 2016 e implantado em 2017 em 18 cidades, são experiências marcantes de cooperação verificadas na Área de Ensino, que ainda não recebem o devido valor na avaliação. Foram destacadas no relatório da AQ (listado nas referências).

Mas além das redes para resultados diretamente em ensino, o relatório também tocou no fato de muitos programas e docentes terem construído uma rede de pesquisa, que aprovou um projeto no edital de Institutos Nacionais de Ciência e Tecnologia (INCT) lançado em 2014 pelo CNPq e concluído em 2016: foi - "INCT-ENSINO - Instituto Nacional de Ciência e Tecnologia em Ensino e Comunicação: Criatividade, Inovação e Tecnologias Digitais na Formação de Formadores." O projeto associou 43 Instituições de Ensino Superior e de Ciência e Tecnologia, articulando 54 grupos de pesquisa com um total de 230 pesquisadores doutores que trabalham o ensino de ciências, a educação matemática, o ensino em saúde e em tecnologias, e o ensino em artes e humanidades, atuando em 47 PPG, das Áreas de Ensino, Educação, Artes e outras, abrangendo todas as regiões do país, 20 estados e 33 cidades. O projeto recebeu o selo INCT, recomendado no mérito, na posição 129 do ranking geral que avaliou 345 projetos de todas as áreas e aprovou 252: entre os $40 \%$ melhores projetos. Todas as propostas foram avaliadas por, no mínimo, três consultores ad hoc internacionais e posteriormente pelo Comitê Julgador, reunido na sede do CNPq em abril de 2016. Mais importante ainda foi perceber que dos 252 projetos recomendados, apenas 3 abordaram temáticas de Educação em seus títulos, o que situa a carência de projetos de pesquisa no campo do Ensino/Educação.

Tal empreitada não foi fácil, tanto pelo grau de articulação que exigiu, como pela dimensão competitiva do edital, reunindo todas as Áreas do conhecimento num mesmo certame. As tecnologias de informação e comunicação, por meio de seus métodos e mídias, são um elo comum à maioria dos grupos. Longe de ser um somatório de projetos individuais justapostos, o programa do INCT-Ensino pretende elevar a qualidade do ensino na educação básica brasileira por meio de diagnóstico e atuação em processos de formação inicial e continuada de professores, e no diálogo propiciado por redes interdisciplinares de colaboração em ciência, arte e tecnologia. Este objetivo será alcançado por meio de três objetivos específicos e 15 metas. Acreditamos que os desafios que emergem da avaliação quadrienal de 2017 dialogam bastante bem com os 3 objetivos do INCT- 
Ensino: \#1 - Ensino e Tecnologias de Informação e Comunicação - TICS (45 grupos): contribuir para a melhoria do ensino na educação básica, com estratégias e materiais inovadores, ênfase em tecnologias digitais de informação e comunicação para educação a distância e em intensa comunicação pública da ciência; \#2 Egressos (27 grupos): fazer um diagnóstico da formação inicial e continuada de professores e formadores, com foco nos egressos de licenciaturas para a educação básica e de mestrados e doutorados em Ensino, e nas suas respectivas experiências; \#3 - Formadores (35 grupos): contribuir para a melhoria da formação de formadores, com diálogo e redes de colaboração interdisciplinares, com formação de educadores, consolidação e ampliação de Redes de Educação e Ciência.

Numa rede tão grande, uma das estratégias de cooperação e convergência de resultados foi a organização por subprojetos temáticos, que poderiam ser fomentados separadamente. São eles: Tema 1- Educação em Ciências, em Química, em Física, em Biologia e Ciências da Terra (33 grupos); Tema 2- Educação Matemática (23 grupos); Tema 3- Educação e Saúde (12 grupos); Tema 4- Ensino e Tecnologias de Comunicação (24 grupos); Tema 5- História e Filosofia da Ciência e da Tecnologia (7 grupos); Tema 6- Ciência e Arte, Linguagens e Identidade (10 grupos); Tema 7- Neurociências, Cognição e Educação (3 grupos); Tema 8Trabalho, Ensino e Desenvolvimento (9 grupos); Tema 9- Inclusão Social, ensino, mitigação da pobreza e educação para a paz (8 grupos). Esses temas também podem ser usados como proposições para a organização de sub-áreas que identifiquem e/ou construam bases epistemológicas comuns e possam nortear a organização do crescimento da própria Área de Ensino.

\section{O que mudar na avaliação?}

Num processo tão complexo como a avaliação quadrienal, a meta de sustentar uma avaliação de qualidade com maior simplicidade é difícil de alcançar. Mas em nossa opinião algumas alterações podem contribuir para o aperfeiçoamento da avaliação, tais como:

a) Fortalecer o valor da cooperação e minimizar o da competição (entre programas): para ampliar o alcance dos processos formativos e reduzir assimetrias regionais. Formar redes temáticas de cooperação para ampliar a taxa de doutoramento na Área e reduzir a distância entre a demanda e a oferta de vagas para mestrado.

b) Ampliar a valorização da Inserção Social.

c) Avaliar também a demanda dos processos seletivos dos programas (número, localização, vínculo profissional dos candidatos).

d) Reduzir o número de produtos registrados que serão considerados na avaliação da produção intelectual, de modo a permitir a leitura e a análise qualitativa, e priorizar a produção docente com os discentes.

e) Avançar na análise temática de títulos e resumos de teses e dissertações, descobrindo seus conteúdos, para além de seus números, identificando destaques nacionais que mereçam forte e coesa divulgação. 
f) Buscar formas de aferir o relacionamento entre a produção científica e seu impacto na formação de professores, na sala de aula e na própria pós-graduação.

g) Estudar forma de integrar as sociedades científicas nacionais e internacionais à Área de Ensino.

\section{Conclusões}

O histórico das cinco sucessivas avaliações pelas quais a Área de Ensino passou desde sua criação, e a percepção clara da evolução dos PPG, da ocupação dos espaços regionais, da multiplicação dos programas a partir de egressos dos PPG mais antigos e nucleadores, permitiram uma visão de que a avaliação quadrienal foi um momento ainda no meio da curva ascendente dessa Área. É tempo de preparar uma maior organização para a Área, para que o crescimento que ainda se antevê possa ser pautado por maior cooperação entre suas subáreas e seus programas, e para que ações e intervenções transformadoras possam ocorrer com grande intensidade e frequência na educação básica, na formação de professores, na educação profissional e tecnológica, no ensino superior em saúde e em outros temas.

Trabalhar na perspectiva coletiva na Área de Ensino por todo o quadriênio nos ensinou a ver com maior clareza seu enorme potencial e suas estratégias de enfrentamento de problemas e adversidades, como escassez de recursos e bolsas. Depositamos nessa comunidade uma enorme confiança sobre seu papel na resistência da sociedade por uma educação pública e de qualidade. Que venham mais e mais desafios. Essa comunidade é forte e dará conta deles. 


\title{
The Education/Teaching Area after CAPES four-year evaluation: out-of-the-box reflections, innovations and challenges in 2017
}

\begin{abstract}
Qualifying people to educate educators in Brazil is an action of great social relevance. In 2017, the Teaching Area registered 157 post-graduation programs, of which 140 were evaluated: 139 plus one network program, the REAMEC, Amazonian Network of Teaching Sciences and Mathematics. We bring here reflections on innovations perceived in the evaluation such as: 1- The evaluation of the integral intellectual production, with four "Qualis"; 2- The indicator "total points per permanent teacher per year"; 3- The combined use of indicators; 4- The creation of "Educational-Qualis"; 5- The internationalization tracking sheet. We highlight networks of cooperation in teaching and research (INCTTeaching) and suggest changes in evaluation, among which: more cooperation and less competition; greater appreciation of "Social Inclusion" subject. We are confident that the Teaching Area community has a huge role in the society resistance fostering public education of high quality.
\end{abstract}

KEYWORDS: education, evaluation, innovation, indicators, cooperation. 


\section{Referências}

NARDI R. 2015. A PESQUISA EM ENSINO de CIÊnCIAS E MATEMÁtICA nO BRASIL. - EdITORIAL. CIÊNC. EDUC. (BAURU) VOL.21 NO.2 BAURU APR./JUNE 2015:I-V. HTTP://DX.DOI.ORG/10.1590/1516-731320150020001

ARAúJO-JoRge T.C., RoçAS G. RELATÓRIO dA AVALIAÇÃo trienAl dA ÁrEA dE ENSINO 20102011-2012. ACESSÍVEL

HTTPS://DOCS.GOOGLE.COM/VIEWER?A=V\&PID=SITES\&SRCID=Y2FWZXMUZ292LMJYFHRYA WVUYWWTMJAXM3XNEDOZNGJINZUOODZIMGYOODMY

\section{ARAÚJO-JoRge T.C., BORBA M.C. SOVIERZOSKI H.H., RELATÓRIO DA AVALIAÇÃO QUAdRIENAL}

DA ÁREA DE ENSINO 2013-2016. ACESSÍVEL EM:
HTTPS://DOCS.GOOGLE.COM/VIEWER?A=V\&PID=SITES\&SRCID=Y2FWZXMUZ292LMJYFGF2Y WXPYWNHBY1XDWFKCMLLBMFSFGD4OJUZYTIWY2Q1NJFMMDZKYJM

Recebido: 2018-02-09

Aprovado: 2018-02-09

DOI: $10.3895 /$ rbect.v10n3.7744

Como citar:

JORGE, T. C. A.; SOVIERZOSKI, H. H.; BORBA, M. C. A Área de Ensino após a avaliação quadrienal da CAPES: reflexões fora da caixa, inovações e desafios em 2017. Revista Brasileira de Ensino de Ciência e Tecnologia, v. 10, n. 3, 2017. Disponível em:< https://periodicos.utfpr.edu.br/rbect/article/view/7744>

Acesso em: xxx.

Correspondência:

Tania C. Araújo Jorge - taniaaj@ioc.fiocruz.br

Direito autoral: Este artigo está licenciado sob os termos da Licença Creative Commons-Atribuição 4.0

Internacional. 